\title{
Effective Learning Outcomes Assessment: The Case of the MIS Department at the UoS
}

\author{
Nadia Rifaat, Oualid Ben Ali, *Waleed M. Al Sabhan, Mohammed Nour \\ University of Sharjah, Sharjah, UAE \\ *walsabhan@sharjah.ac.ae
}

\begin{abstract}
Accrediting organizations now mandate the development of learning outcomes (LO) and the methods to assess those learning outcomes for national and international institutions of higher learning. Because of this, academic institutions pay greater attention to the development and assessment of these LO. There are two types of learning outcomes: course outcomes and program outcomes. This paper presents an empirical study that examines both kinds of LO in a case study of one course (title: Database Fundamental and Applications, number: 0303331) within the Management Information System (MIS) department at the University of Sharjah (UoS), United Arab Emirates and presents the following with regard to this case study: 1) the development process of the LO for this specific course; 2) the data collection process, and 3) the data collected related to the assessment instruments for both the course and program LO (course learning instructions, course exams, course projects, students' records, students' grades, course reports, course evaluation, instructor evaluation, exit surveys, employer surveys, and job placement indicators); 4) the methods of assessment of the LO based on the analysis of the collected data using a variety of analysis technique and tools; and 5) the usage of the analysis results in successive semesters in order to improve the MIS courses and program. The findings of this empirical study suggest several areas for improvement. One improvement is the addition of more practice-based learning components. Additionally, the study shows that the enhancement of the course material, the improvement of teaching strategies, and the usage of technology and its infusion into the learning process are areas that can improve LO. Overall, the method of LO development and assessment described in this empirical examination has shown a positive effect on the courses and program in the MIS department, and it is believed that the results can be generalized for use by others in developing and assessing LO in other learning institutions.
\end{abstract}

Keywords: Learning outcomes assessment, course outcomes, learning outcomes, measurement, outcomebased education (OBE), program outcomes, accreditation, MIS program, and program metrics.

\section{Introduction}

In recent years, greater attention is given to developing learning outcomes for academic programs as well as to developing meaningful assessment methods and tools to evaluate these outcomes (Besterfield-sacre, et al., 2000). Accrediting organizations now mandate the development of learning outcomes (LO) and the methods to assess those learning outcomes for national and international institutions of higher learning. Because of this, academic institutions pay greater attention to the development and assessment of these LO. There are two kinds of learning outcomes: course outcomes and program outcomes. The course outcomes should describe what students are expected to learn from an individual course, while program outcomes should describe what students are expected to accomplish after completing the coursework from the program (Hashim \& Mohd Din, 2009). Maki (2002) pointed out that learning outcome assessments should be based on institutional curiosity to seek answers to questions about student learning: Why do they learn? How well do they learn? When do they learn? Maki (2002) explores how developing and fostering students' learning are influenced by pedagogies and educational experiences. He points to four actions that might improve student learning outcomes that are based on assessment results: 1) innovations in pedagogy or integration of diverse methods of teaching and learning into a program of study, 2) redesign of a program, 3) re-conceptualizing the role of advising, or 4) establishing stronger connections between curriculum and non-curriculum activities. Assessment is a systematic and ongoing process of collecting, interpreting, and acting on information related to the goals and outcomes developed to support the mission and purpose of an institution (Oster, 2003). According to Acharya (2003), assessment should help us answer the following questions: (1) what do we want the students to learn? (2) Why do we want them to learn it? (3) How can we help them to learn it? In addition (4), how do we know what they have learned? In addition, Oster pointed out that assessments should help us to improve what educators are doing. Assessment begins with articulating and developing measurable outcomes. In this paper, we provide the process we have adopted in order to assess the learning 
outcomes of our courses and program of Management Information Systems in a way that will meet requirements for accreditation from the Local Accreditation Council. We also show the benefit of adopting such process on the improvement of learning. This process can be used as a guide for planning and conducting outcomes assessment for other programs in other areas

\section{Literature Review}

Effective Student Learning Outcomes: Competency-based learning and mastery learning are movements that began in elementary and secondary schools and eventually moved to higher education. Designs for mastery learning are rooted in agreed-upon intended outcomes, which emphasize assessment of individual achievement (Ewell, 2009). These statements may be written at the course, program, or institutional level and are designed to convey expectations to students and faculty. Huba and Freed (cited in Barkley, 2010) further defined the characteristics of effective learning outcomes:

- are student-focused rather than professor-focused;

- focus on the learning resulting from an activity rather than on the activity itself;

- reflect the institution's mission and the values it represents;

- are in alignment at the course, academic program, and institutional levels,

- focus on important, non-trivial aspects of leaning that are credible to the public;

- focus on skills and abilities central to the discipline and based on professional standards of excellence;

- are general enough to capture important learning but clear and specific enough to be measurable; and

- Focus on aspects of learning that will develop and endure but that can be assessed in some form now (Barkley, 2010).

A variety of models of student learning outcomes abound, although some outcomes, such as problemsolving, critical thinking, and communication skills, are considered to be necessary for all college graduates, and many student learning outcomes are designed to integrate these essential learning outcomes into the program. The Association of American Colleges and Universities developed a list of essential learning outcomes for students at all levels to accomplish, divided into four categories: knowledge of human cultures and the physical and natural world, intellectual and practical skills, personal and social responsibility, and integrative and applied learning (Kuh, 2008). Astin (1991) organized student outcomes into affective and cognitive domains. Lenning, et al., (1977) developed a framework to "accommodate information about the full range of postsecondary education outcomes" ( $p$. 1). Building on the work of Astin's IEO assessment model, Terenzini (1997) developed a comprehensive taxonomy of 12 specific domains of student outcomes:

- Communication and computational skills

- Higher-order cognitive and intellectual development

- Content learning

- Occupational preparation

- Workplace skills

- Educational success

- Success in transitions

- Economic benefits

- Psychosocial development

- Attitudes and values

- Civic development

- Quality of life. (pp. CI-C3)

Even though social and personal responsibilities are often cited as desirable, most student learning outcomes in higher education are still confined to cognitive output measures such as critical thinking, effective communication, and problem solving, and shy away from outcomes such as empathy, selfcomprehension, integrity, or teamwork (Shavelson \& Huang, 2003). Achievement of student outcomes relies on authentic assessment measures that replicate skills, abilities, and judgments used by professionals in the field (Ewell, 2002a). Authentic assessments require that students make connections between the abilities and skills they have developed through prior education and experiences, and the discipline-based knowledge and skills they have acquired in the major (Ewell, 2002b). Unpublished reports of curricular changes based on assessment results abound, from changes in teaching strategies 
that encourage greater student understanding to rearranging the order of topics to reinforce concepts, or refining courses to support writing across the curriculum. While not a major focus of published reports, assessment results have been utilized internally for improvement at a myriad of institutions. One such example is the revision of the educational leadership doctoral program at Iowa State University (Huba et al., 2006). There are scenarios in which assessment results have prompted curricular changes that have in turn increased student learning. However, the lack of consistently documented successful results from assessment of student learning is evidence of the need for greater attention to assessment and institutional effectiveness, including a consensus on what constitutes deep collegiate learning (Ewell, 2008). This highlights the need for leaders at all levels of higher education to be trained in defining, developing, and implementing effectiveness plans that are based on the mission of the institution, integral to student learning outcomes, integrated into strategic planning at all levels of the institution, and the results are utilized in a continuous and documented feedback loop that extends to all constituents of the institution (Angelo, 2002; Ewell, 2002a). "Sustainable assessment is linked to processes that academics value such as strategic planning, professional development, and program review" (Banta, 2008). An effective assessment professional needs to integrate both qualitative and quantitative methods into a program evaluation framework in which the methods of gathering, interpreting, and presenting data are of prime importance in preparing to lead an assessment effort. Leadership and organizational studies can surround that preparation (Banta, 2008). Assessment must focus on both process and product. Effective assessment is a blend of many factors, not based on the division between accountability and improvement but designed "to see how the two mix in day-to-day higher education practice and policy" (Doherty, 2005) such that the focus is on "effectiveness, incentives, collaboration among constituency groups, flexible and campus-specific assessment programs, and links to strategic planning".

Learning Outcome Development: Learning outcomes describe what students should demonstrate for knowledge, skills, and values on completion of a course, a span of several courses, or a degree program (Oster, 2003). A clear statement of learning outcomes serves as the foundation to assess the effectiveness of the teaching and learning process (Kember, et al., 2009). According to Oster, the three measurable essential components of a learning outcome are: (1) student learning behaviors, (2) appropriate assessment methods, and (3) specific student performance criteria. Students' learning behaviors describe what students should demonstrate by the completion of the course. Assessment methods are tools and techniques that measure the extent to which stated learning outcomes are achieved. Student performance criteria should be expressed in specific and measurable terms that are acceptable to a specific course or series of courses. A variety of methods, qualitative and quantitative, direct and indirect, should be used to assess the learning outcomes. A simple letter grade $(\mathrm{A}, \mathrm{B}+, \mathrm{B})$ does not provide adequate feedback to a student's performance, because the letter grade does not identify the strengths and weaknesses of individual learning outcomes. The addition of rubrics, which address the individual outcome components, to the grading system allows that system to pinpoint the weaknesses and strengths of the student's performance. Learning outcomes of a program/course should contain precise definitions. Outcomes are clear, observable demonstrations of student learning that occur after a significant set of learning experiences. Typically, these demonstrations, or performances, reflect three things: (1) what the student knows, (2) what the student can actually do with his/her knowledge, and (3) the student's confidence and motivation in carrying out the demonstration Pang, et al. (2009). A well-defined learning outcome contains clearly defined content or concepts and is written as a well-defined process that begins with either directives or requests such as explain, organize, or produce (Spady \& Marshall, 1994).

Outcomes Assessment: Teaching and learning are interwoven with outcomes assessment, which is most simply defined as the assessment of student learning (Shavelson, 2007). The Perry (1970) scheme, which included the importance of student understanding of knowledge, continues to inform teaching and learning and can be used as a framework for outcomes assessment with its emphasis on the "transformation of the learner rather than simply transmission of knowledge" (Moore, 1994). The two most important aspects for assessment that emerged from the Perry scheme are that educators must acknowledge and honor the meaning that students ascribe to knowledge and learning, and how faculty chooses to assess an outcome is an act of making meaning (Moore, 1994). Another framework that has been used for outcomes assessment is Astin's input-environment-output (IEO) model, which includes student inputs (what they bring to a program), educational environment (including the experience of education), and the outputs or outcomes intended by the program (Astin, 1991; Banta, 2002; Thurmond \& Popkess-Vawter, 2003). An additional model was proposed by Maki (2002) in three major parts: determining institutional expectations; determining timing, identifying cohorts and assigning responsibilities; and interpreting and sharing results. Banta (2002) synthesized literature on assessment 
to describe the three phases of effective outcomes assessment in higher education as the planning, implementation, and improving and sustaining phases.

Outcomes Based Education: Outcomes-based education (OBE) is a repeating model of education reform. This model is based on the process of collecting information that will tell an organization whether the services, activities, or experiences it offers are having the desired impact on those who partake on them. In other words, is the organization making a difference in the lives of the individuals it serves? This model is student-centric and focuses on empirical assessment of student learning outcomes. OBE does not require a specific teaching style and is therefore different from traditional education that focuses on what resources exist for the students. OBE requires that students show that they learned expected skills and content (David, 2009). Acharya (2003) has mentioned that OBE has many advantages, of which some are:

- $\mathrm{OBE}$ is able to measure- 'what the students are capable of doing'- something which the traditional education system often fails to do;

- OBE goes beyond 'structured tasks' (e.g. memorization) by demanding that students demonstrate their skills through more challenging tasks like writing project proposals and completing the projects, analyzing cases studies, and giving case presentations, etc.;

- OBE also identifies higher levels of thinking (e.g. creativity, ability to analyze and synthesize information, ability to plan and organize tasks, etc.).

- Acharya (2003) has also pointed out some disadvantages of OBE as proposed by its opponents:

- OBE is not about academics such as reading, writing, and arithmetic, but OBE are about attitudes and outcomes;

- OBE offers no method of accountability to students, parents, or teachers, so it is expensive.

The Role of Accreditation: Accreditation has increased institutional accountability for what is taught and how effectively the institution is following the mission and meeting the goals. The emerging "scholarship of assessment" (Banta, 2002) has moved the focus toward teaching and learning "what is, what ought to be, and what is possible". There is wide acceptance among assessment practitioners that the purpose of assessment is not in the specific techniques and methodologies but in the use of the results to improve teaching and learning (Banta, 2002; Ewell, 2009). One of the challenges facing the assessment movement will be to partner or collaborate with other somewhat isolated reform movements on campus to "create an integrated approach to transforming teaching and learning" (Ewell, 2009). Student learning outcomes should replace organizational inputs as indicators of institutional effectiveness according to the systems-analysis view of accountability. Following the request from the Council on Postsecondary Accreditation that assessment of student learning be included in self-studies and in strategic planning for change, a barrage of reports emerged asking for public accountability for assessment results, program goals, outcomes, and implementation (Allen, 2006). The public outcry to improve institutional effectiveness in raising student-learning outcomes led all six regional accrediting bodies to include outcomes assessment measures as a component of institutional effectiveness. For assessment to fully evolve from a movement into a culture, an emphasis must continue on fostering student learning by focusing on curricular improvement leading to performance-based attainment (Ewell, 2009; Ewell, $2002 \mathrm{~b}$ ). The development of a strong institutional pattern for student outcomes assessment depends in part on leadership that is externally oriented in understanding state and accreditation mandates, strategically savvy in awareness of the outcomes assessment processes and how to integrate it the broader educational change and improvement initiatives, and has the technical understanding of the design and analysis of the assessment process.

The Case of the MIS Department, UoS: Because the implementation of OBE is now a requirement for obtaining accreditation from the Local Accreditation Council in Abu Dhabi, UAE, it is being implemented in the Department of Management Information Systems at UoS, despite ongoing reservations about OBE. The faculty members of this department believe that the approach is appropriate for the types of students that enroll, and above all, the local accreditation body requires it. The OBE implementation in the Bachelor of MIS programs is designed to equip students with a solid foundation in the field of information systems as well as to give them "hands-on" training and experience in a variety of information technology applications. Students are expected to acquire a breadth of understanding across the information technology areas. This paper describes strategies of OBE implementation at UoS, MIS department, especially with respect to assessment strategy. The Department of Management Information Systems (MIS), which was launched in the fall semester of the academic year 1997-1998, is a part of the College of Business Administration at the UoS. In response to feedback from constituent groups, including graduating students, alumni, and employers, the department has created an updated program of study, 
which became effective during the academic year 2007-2008. The new program enables the Department to cope with a growing market demand of MIS professionals. The new program reflects the results of internal program review and assessment.

UoS MIS Department Program Learning Outcome Development: The MIS Department at UoS decided to develop a set of program learning outcomes. Faculty members were asked to develop outcomes that they thought were important for the program. They were asked to consult with the relevant literature to develop meaningful and measurable outcomes (Lau, 2009). They were also asked to consult with other educational institutions where similar programs were available, as well as professional organizations, and accreditation agencies to learn more about the outcome development process. Exhaustive research and a symposium called "Outcome-Based Education and Assessment" that was held at the UoS on January 2006, was useful in guiding the faculty members in this endeavor; the faculty members developed several outcomes for the MIS Department's program, and from this list the MIS Department was able to select eleven (11) measurable outcomes for its program. The American Association of Higher Education's "nine principles of good practices for assessing students' learning" were used in the outcomes selection process (AAHE, 2009). The MIS Department also used a number of other research documents from the AAHE's assessment web. The MIS Department's hope is that the graduates of its program will be able to show that they have accomplished these eleven outcomes upon receiving a degree from the MIS program. Table 1 shows the learning outcomes developed by the MIS Department program.

Table 1: The eleven MIS Program Outcomes

a. Apply knowledge of management and computing to business problem solving,

b. Analyze, design and implement Information Systems for a variety of problems,

c. Manage information system development life cycle,

d. Work in teams,

e. Gain an understanding of professional, social and ethical responsibilities,

f. Communicate effectively both orally and in writing,

g. Acquire the broad education necessary to understand the impact of IT in a global and societal context

h. Recognize the need for and engage in life-long learning,

i. Acquire knowledge of contemporary issues,

j. Use the techniques, skills and modern IT tools necessary for best practices in the field, and

k. Apply decision models to managerial problems

Table 2: MIS Course Offerings

\begin{tabular}{lll}
\hline \multicolumn{2}{l}{ Course No. } & \multicolumn{2}{l}{ Course Title } \\
\hline \multicolumn{2}{l}{ Departmental Core } \\
Old no./New no. & \\
0303102 & 0303210 & Business programming I \\
0303435 & 0303390 & Internship in MIS \\
0303330 & 0303350 & Business Data Telecom. \& Networks \\
0303331 & 0303240 & Database Fundamentals \& Applications \\
0303335 & 0303332 & System Analysis \& Design \\
0303336 & 0303333 & Project Management \\
0303337 & 0303310 & Business Programming II \\
0303430 & 0303440 & DB Management \& Administration \\
0303432 & 0303495 & Project in MIS \\
Course No. & & Course Title \\
Departmental Electives & \\
0303338 & 0303320 & Electronic Commerce \\
0303439 & 0303420 & Web Applications Development \\
& & \\
- & 0303433 & Enterprise Development \\
0303436 & 0303436 & Decision Support Systems \\
0303431 & 0303450 & Information Security \\
- & 0303490 & Special Topics in MIS \\
\hline
\end{tabular}


UoS MIS Department Course Learning Outcome Development: Once the MIS program learning outcomes were developed, the MIS department evaluated how these outcomes could be accomplished through its course offerings. Thus, the faculty members in the MIS Department developed a set of outcomes for each of their courses, keeping in mind that there must be a match between these course outcomes and the program outcomes. In other words, the stated program outcomes must be accomplished through the course outcomes. Faculty members who are teaching the individual courses were asked to consider the program outcomes and see how these outcomes can be applied in their courses. In addition, the outcomes reflect what a faculty member would like his/her students to accomplish at the completion of that particular course. The importance of measurability and clarity of the course outcomes was emphasized. Faculty members developed a set of learning outcomes for each course from which the MIS Department matched five or six outcomes for each individual course. The current MIS course offerings (course numbers and corresponding course titles) are listed in Table 2 above.

UoS MIS Department Learning Outcome Assessment: The assessment of student learning, student development, and program outcomes is essential to the health and vitality of academic programs at the UoS. The main purpose of implementing learning outcomes assessment is to improve students learning through improved curricula and improved instruction (Houshangi, 2003). The UoS's effectiveness system has been developed to support the assessment and improvement of all programs in all colleges in meeting their stated goals and outcomes. In this section, we briefly describe the processes used to produce and assess the Student Learning Outcomes (SLOs) in the MIS Department. In addition, details are discussed about how course/program effectiveness tools are used to enhance the MIS Program's performance in achieving its goals and expected outcomes. The MIS Department performs outcomes assessment at two levels: Course and Program. Once the learning outcomes for the program and the courses are developed, it is important to assess those outcomes. In the following section, we present the assessment approach. The approach adopts a bottom-up assessment meaning that first the course LOs are assessed and then, based on this assessment, the program LOs are assessed (see Figure 1 below).

\section{Figure 1: Methodology Chart-From Program to Course Outcomes}

\section{MIS PROGRAM LEVEL OUTCOMES

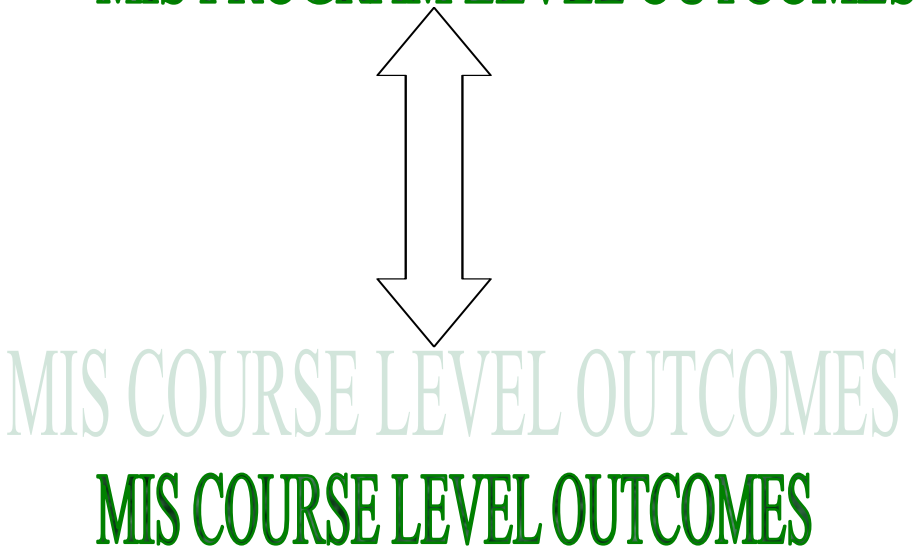

UoS MIS Department Course Learning Outcomes Assessment: The LO Assessment a Course Embedded Assessment (CEA) process that focuses on a set of core classes required of all students in the major was established. Each course has detailed objectives, specific course outcomes, and indicators that are monitored to ensure successful achievement of those outcomes. On a semester basis, the Course Coordinators for courses covered by CEA present a report to the Department faculty reflecting on student achievement for the specific course outcomes, whether prerequisites are appropriate, student reaction to the course, and suggested changes if any. This process is useful because it enables faculty who are not directly involved in specific courses from the CEA group to get a full understanding of the courses in the CEA group and adjust their own courses. It allows new faculty and part-time faculty to acquire a thorough understanding of the curriculum and become familiar with the challenges by perusing the annual CEA reports (Felder and Brent, 2003). In addition, the process ensures that faculty in related courses interact with each other on a regular basis when preparing the CEA report for a particular course. Equally 
important, the CEA reports provide the documentation to illustrate how the faculty uses assessment results for ongoing program improvement (David, 2009; Timm, 2009). For courses that are not part of the CEA group, individual faculty members teaching the courses are responsible for course-level assessment. Each course has clearly defined objectives and a set of measurable outcomes that contribute to one or more of the program's SLOs. The faculty member teaching the course is responsible for reporting any major issues that are revealed from outcomes assessment and initiating appropriate changes to ensure that the course objectives are met successfully. The outcomes assessment at the course level is carried out by using a variety of assessment tools:

- Student records analysis

- Learning instrument process

- Capstone course evaluation

- Student Evaluations (course/teacher)

- Internship Reports

- Course file analysis/evaluation

- Job placement indicators

\section{Methodology}

Process: used to produce and assess the SLOs.

Result: improve student learning through improved curricula and improved instruction.

- Develop learning outcomes for the MIS Program.

- (11 outcomes were developed). See page 3 /Program Learning Outcome development

- Develop a set of outcomes for each of the courses.

- (5-6 outcomes were developed) see course learning outcome development on page 3.

- The Program outcomes is accomplished through the outcomes of each course

- Measurable outcomes (weighted)

- At the course level on three points

$\circ$ classroom performance

○ homework

$\circ$ course project and course files

The MIS Department started implementing outcome-based assessment in the fall semester of the 2006/2007 academic year. The Department piloted the new assessment scheme on the final exam of that semester. In the three subsequent semesters, the scheme was expanded to cover the second exam, the first exam, and the semester project. For the purpose of this paper, the Database Fundamentals \& Applications course (course number 0303331) is used as an example. The course outcomes stated in Table 3 are developed to augment the program outcomes. In order to assess and evaluate the course outcomes A-F and their achievement, we gave a weight to each outcome. These weights were measured by using three course enhancement processes: a) classroom performance assessment, b) homework assignments, c) course projects \& course files.

Table 3: Courses outcomes: Database Fundamentals \& Application (course number 0303331)

Course Outcomes: Student who successfully complete this course will be able to:

Analyze a business database application and create conceptual mode using the Entity Relationship Diagram;

Use Microsoft Access to create tables, queries, forms, reports, and macros;

Implement (in a group) a database application with Microsoft Access;

Demonstrate a clear understanding of the relational database model and basic database concepts;

Demonstrate an understanding of good database design guidelines, techniques and principles, including normalization;

Use SQL to create and manipulate relational database objects.

The classroom performance assessment included midterm exam one (T1) (15\%), midterm exam two (T2) (15\%) a final exam (T3) (40\%) and a final project (Project) (15\%). (Note: Vi and Wi refer to student score and weight given to the component, respectively). The reported performance results reflect these components, which account for a maximum of $85 \%$ of the final score. The remaining $15 \%$ reflect the 
contribution of homework assignments, quizzes, and lab tests. These components were to be implemented in the spring semester of the academic year 2008/2009. Table 4 shows the outcomes assessment for the fall semester of the academic year 2007/2008. A number of inferences can be developed. The total averages for all specified outcomes are good to very good as average grades vary from $81 \%$ to $91 \%$, except for Outcome D (demonstrate a clear understanding of good database design guidelines, techniques, and principles, including normalization) where the average is $67.85 \%$. This indicates that the current teaching method does not support the learning outcome. Results of one semester are not indicative; therefore taking more than one semester gives us a more relevant perspective. The results and comparison of four semesters, the fall and spring semesters of 2006/2007 and 2007/2008 are summarized in Table 5 and Figure 2.

Table 4: Database Fundamental \& Applications assessment (fall semester of the academic year 2007-2008)

\begin{tabular}{|c|c|c|c|c|c|c|c|c|c|c|c|}
\hline & T1 & & T2 & & T3 & & Proje & & Total & Weight & $\%$ \\
\hline outcomes & V1 & W1 & V2 & W2 & V3 & W3 & $\mathrm{Vp}$ & Wp & $\mathbf{V}$ & $\mathbf{W}$ & 85 \\
\hline $\mathrm{A}$ & 16.59 & 20 & 0 & 0 & 5.45 & 7 & 2.275 & 2.5 & 11.87 & 14.50 & $81.88 \%$ \\
\hline B & 0 & 0 & 0 & 0 & 0 & 0 & 2.275 & 2.5 & 2.28 & 2.50 & $91.00 \%$ \\
\hline $\mathrm{C}$ & 0 & 0 & 0 & 0 & 0 & 0 & 2.275 & 2.5 & 2.28 & 2.50 & $91.00 \%$ \\
\hline D & 0 & 0 & 15.36 & 21 & 4.57 & 8 & 2.275 & 2.5 & 10.69 & 15.75 & $67.85 \%$ \\
\hline $\mathrm{E}$ & 23.69 & 30 & 20.27 & 27 & 10.10 & 12 & 2.275 & 2.5 & 23.36 & 28.75 & $81.27 \%$ \\
\hline $\mathrm{F}$ & 16.63 & 10 & 9.65 & 12 & 9.00 & 13 & 2.275 & 2.5 & 17.84 & 21.00 & $84.97 \%$ \\
\hline Total & 56.90 & 60.00 & 45.28 & 60.00 & 29.12 & 40.00 & 13.65 & 15.00 & 68.32 & 85.00 & $82.99 \%$ \\
\hline Weights & 15 & & 15 & & 40 & & 15 & & 85 & & \\
\hline
\end{tabular}

Table 5: Database Fundamental \& Applications assessment (multiple semesters)

\begin{tabular}{|c|c|c|c|c|c|c|c|c|c|c|}
\hline & \multicolumn{3}{|c|}{ F06/07 Change } & \multicolumn{3}{|c|}{ S06/07 Change } & \multirow{2}{*}{$\begin{array}{l}\text { F07/08 } \\
\%\end{array}$} & \multicolumn{2}{|c|}{ Change } & \multirow{2}{*}{$\begin{array}{l}\text { S07/08 } \\
\% \\
\end{array}$} \\
\hline & $\%$ & $\%$ & Trend & $\%$ & $\%$ & Trend & & $\%$ & Trend & \\
\hline A & 78.05 & & & 67.95 & 13.9 & & 81.88 & & & $77.04 \%$ \\
\hline B & & 5.2 & & 82.24 & & & & & & \\
\hline $\mathrm{C}$ & & & & 82.24 & & & & & & $0 \%$ \\
\hline 2 & 76.83 & -12.77 & & 64.06 & 3.7 & Incr & 67.85 & & & $61.00 \%$ \\
\hline E & 94.33 & -14.76 & Decrease & 79.57 & 1.70 & Incre & 81.27 & -5.27 & Decrease & $76.00 \%$ \\
\hline $\mathrm{F}$ & & & & 73.30 & 11.67 & Incre & 84.97 & & & \\
\hline Total & 84.11 & -8.89 & Decrease & 74.89 & 8.10 & Increase & 82.99 & -10.99 & Decrease & $71.61 \%$ \\
\hline Weights & 55 & & & 70 & & & 85 & & & 80 \\
\hline
\end{tabular}

Figure 2: Course assessment over 4 years (multiple semesters)

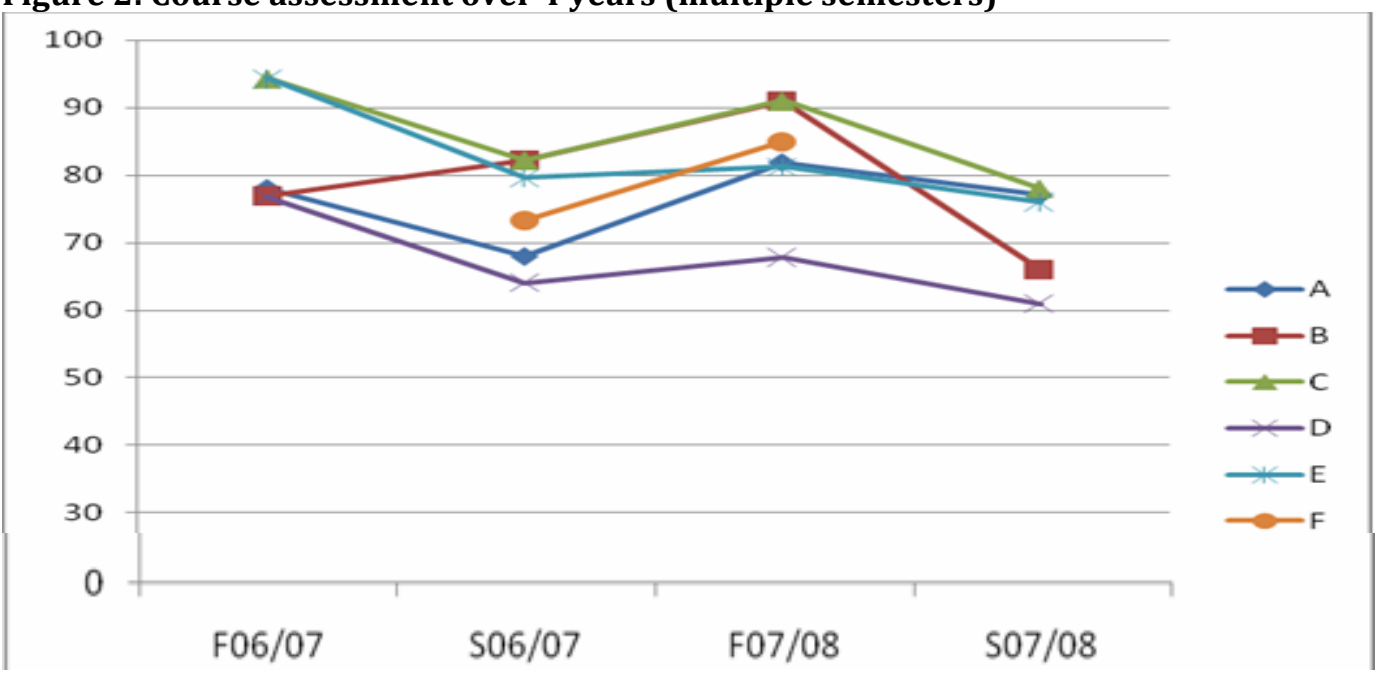


Analysis, Evaluation, and Recommendations: The MIS Department started implementing the outcomebased assessment in most of its courses in the fall semester of the academic year 2006/07. The assessment in the following semester, Spring 2006/07, has shown a decline in the achievement level of most of the outcomes (see Table 5 and Figure 2). This is, in part, because the fall semester assessment involved only the final exam and the semester project, as the decision to start this type of assessment came towards the end of the semester. The semester project is designed to apply and test the skills and concepts learned throughout the semester. In the spring semester of the academic year 2006/07, the department extended outcome-based assessment to include the second midterm exam, in addition to the final exam and the project. Outcome A (Analyze a business database application and create conceptual mode using the Entity Relationship Diagram) and the outcome D (Demonstrate a clear understanding of the relational database model and basic database concepts), in particular, had the lowest achievement scores of $67.95 \%$ and $64.05 \%$, respectively. This probably indicates a need for more practical components in the course: assignments, lab practice, and projects. Components that are more practical had been planned for the next semester to correct this deficiency. The outcome-based assessment was extended again in the fall semester $2007 / 2008$ and spring semester 2008 to include all three exams, plus the project. The performance of outcomes A and D were now significantly improved: $81.88 \%$ and $67.65 \%$, respectively, in the fall semester of the academic year 2007/2008. The performance for all outcomes have improved, compared to the previous semester (spring semester of the academic year 2006/2007). This was due, in part, to the decision to add more practice-based learning components to the course curriculum to fix the deficiency that was revealed at the end of the spring semester. However, there was a downward trend in the following spring semester, and the following actions were planned for the fall semester of the academic year 2008/2009 to reverse the trend and improve the performance:

- Plan the course to be completed at most one week prior to the end of the semester. The last week can then be used to review and re-enforce the understanding of the more difficult concepts.

- Give more graded homework and practice assignments on the material and concepts of Outcome $\mathrm{D}, \mathrm{E}$, and F.

Program Learning Outcomes assessment: Mapping of Course Outcomes Assessment; The Department then developed a table to show the relationship between program outcomes and courses offerings (see Table 6). The Department faculty members also agreed that when a new course is developed in the future, greater attention to the course outcomes is required to see how this new course will satisfy the program outcomes. By adding new columns in Table 6, the MIS Department faculty members will be able to get a quick view of the relationship between the course and program outcomes.

Table 6: A matrix relating program outcomes to course outcomes

\begin{tabular}{|c|c|c|c|c|c|c|c|c|c|c|c|c|c|}
\hline \multirow[t]{2}{*}{$\begin{array}{l}\text { Program } \\
\text { Outcome }\end{array}$} & \multicolumn{13}{|c|}{$\begin{array}{l}\text { Outcomes of Major Courses Mapped to Program Outcomes (last three digits of course } \\
\text { code) }\end{array}$} \\
\hline & 102 & 230 & 231 & 330 & 331 & 332 & 333 & 337 & $\underline{338}$ & 430 & 432 & $\underline{436}$ & $\underline{439}$ \\
\hline $\mathrm{a}$ & $\begin{array}{l}\mathrm{A}, \mathrm{B}, \mathrm{C} \\
\mathrm{D}, \mathrm{E}, \mathrm{F}\end{array}$ & $\begin{array}{l}\text { A,B,C,D, } \\
\mathrm{E}, \mathrm{F}\end{array}$ & $\begin{array}{l}\mathrm{A}, \mathrm{B}, \mathrm{C} \\
\mathrm{D}, \mathrm{E}\end{array}$ & A,C & $\begin{array}{l}\mathrm{A}, \mathrm{C} \\
\mathrm{D}, \mathrm{E}\end{array}$ & $\begin{array}{l}\text { A,BD, } \\
\text { FG }\end{array}$ & $\begin{array}{l}\text { E A,B,C,D, } \\
\text { E,F }\end{array}$ & $\begin{array}{l}A, B, D \\
F, G\end{array}$ & $\mathrm{E}, \mathrm{F}$ & $\begin{array}{l}\text { ACD } \\
\text { EFH }\end{array}$ & $\begin{array}{l}\mathrm{B}, \mathrm{C}, \\
\mathrm{D}, \mathrm{F}, \mathrm{G}\end{array}$ & $A, B$ & $\begin{array}{l}\text { A,C,E,F, } \\
\text { G,H,K }\end{array}$ \\
\hline b & $\begin{array}{l}\mathrm{C}, \mathrm{D}, \mathrm{E}, \\
\mathrm{F}, \mathrm{G}, \mathrm{I}\end{array}$ & $\begin{array}{l}\mathrm{A}, \mathrm{B}, \mathrm{C}, \mathrm{D}, \\
\mathrm{E}\end{array}$ & $\begin{array}{l}\mathrm{A}, \mathrm{B}, \mathrm{C} \\
\mathrm{D}, \mathrm{E}\end{array}$ & A,B & $\begin{array}{l}\mathrm{A}, \mathrm{B}, \\
\mathrm{D}, \mathrm{E}\end{array}$ & $\mathrm{A}, \mathrm{B}$ & $\begin{array}{l}\text { A,B,C,D, } \\
E, G\end{array}$ & $\begin{array}{l}\text { A,B,D, } \\
F, G\end{array}$ & $\mathrm{C}$ & $\begin{array}{l}\mathrm{A}, \mathrm{B}, \mathrm{C} \\
\mathrm{D}, \mathrm{E}, \mathrm{F}, \mathrm{I}\end{array}$ & $\begin{array}{l}\text { B,D, } \\
\text { E, F,G }\end{array}$ & $\mathrm{A}, \mathrm{B}$ & $\begin{array}{l}\text { A,C,D,E, } \\
\text { F,G,I,J }\end{array}$ \\
\hline c & & & & B & $\mathrm{B}, \mathrm{E}$ & $\mathrm{C}$ & & & & A & $\mathrm{A}, \mathrm{B}, \mathrm{D}$ & & A \\
\hline d & & & & D & & C & & & & & $\mathrm{C}$ & $\mathrm{C}$ & \\
\hline e & & & & & & $\mathrm{C}$ & & & & & & & \\
\hline $\mathrm{f}$ & & & & D & & & & & & & $\mathrm{C}$ & & \\
\hline g & & & & D & & & & & & & & & \\
\hline h & & & & & & & & $\mathrm{F}, \mathrm{G}$ & $\mathrm{C}, \mathrm{F}$ & & & & \\
\hline i & $\begin{array}{l}\mathrm{C}, \mathrm{D}, \\
\mathrm{E}, \mathrm{G}\end{array}$ & $\begin{array}{l}\mathrm{A}, \mathrm{B} \\
\mathrm{C}, \mathrm{E}\end{array}$ & $\begin{array}{l}\mathrm{A}, \mathrm{B} \\
\mathrm{C}, \mathrm{E}\end{array}$ & & & & $\mathrm{A}, \mathrm{B}, \mathrm{C}, \mathrm{E}$ & $\begin{array}{l}\mathrm{A}, \mathrm{B}, \mathrm{C} \\
\mathrm{D}, \mathrm{E}, \mathrm{F}\end{array}$ & $\begin{array}{l}\mathrm{A}, \mathrm{B} \\
\mathrm{D}, \mathrm{E}\end{array}$ & $\mathrm{I}, \mathrm{J}$ & & & B \\
\hline j & & & $\begin{array}{l}\text { C,D, } \\
\mathrm{E}\end{array}$ & $\mathrm{C}$ & C,D & $\begin{array}{l}\text { A,B,D, } \\
\text {,F,G }\end{array}$ & EC,G,H & $\begin{array}{l}\text { C,D, } \\
\text { E,F,G }\end{array}$ & $\begin{array}{l}\text { B,C, } \\
\text { D,E,F }\end{array}$ & $\begin{array}{l}\text { B,I, } \\
\text { J }\end{array}$ & $\mathrm{C}, \mathrm{E}$ & $A, B$ & B,D,J,M \\
\hline $\mathrm{k}$ & & & & & & $\mathrm{F}$ & & & & G & & $\mathrm{C}$ & \\
\hline
\end{tabular}


Table 6 shows a mapping of the courses and the MIS program outcomes. The courses are divided into two groups: Required MIS courses and elective courses (bold and underlined). Students are required to take twelve MIS courses from the MIS program to receive an MIS degree. "A, B, C, D, E, F, G." mark is placed in a cell to show the course outcomes and which course is used to achieve a particular outcome. For example, from Table 6, it is clear that the Database Fundamentals \& Applications course is addressing four (a, b, c, \& j) of the program outcomes. Also, MIS 0303210 (Business programming I) is used to achieve outcomes $\mathrm{a} \& \mathrm{~b}$. The same is true with all the other courses as outcomes a and $\mathrm{b}$ represent the core outcomes of the MIS program. A further analysis of the table shows that outcome $\mathrm{c}$ is accomplished through MIS 0303350, 0303240, 0303335, 0303440, 0303495 and 0303420. "Working in Teams" is covered by outcome d will be addressed in our classes MIS 0303350, 03033325, 0303495 and 0303436. Students are expected to engage in lifelong learning in MIS 0303310 and 0303320. This requirement will address outcome $h$. Contemporary issues are covered in MIS 0303390, 0303320, 0303420 \& 0303450.Techniques, skills and modern IT tools necessary for best practices in the field are represented in all courses, and therefore, the MIS Department faculty decided that outcome j will be addressed in all classes. Applications of Decision Models to managerial problems are required in courses MIS 0303335, 0303440, 0303436 and this requirement will address outcome $\mathrm{k}$.

\section{Assessment and Results}

The following four tables include assessment data that demonstrate the effective achievement of the MIS program outcomes. Using $65 \%$ as a cutoff for contributing effectively to achievement of program outcomes, the results suggest that four of the eight courses in Table 7 contributed to meeting program outcomes. The other four courses have roughly half of their contribution percentages below the cutoff level, indicating a weakness in their contribution to the program outcomes. Table 7 presents the program outcome achievement for the Spring 2006/2007 semester, and shows an improvement over the fall $2006 / 2007$ semester. In the spring semester, only two entries are below the $65 \%$ cutoff level. Similarly, looking at Table 7 we can see that only six entries do not meet the cutoff criterion. Finally, Table 8 indicates for the Spring 2007/2008 semester considerable improvement, with all the entries now exceeding the cutoff criterion, demonstrating that the program outcomes have been effectively achieved. The semester by semester assessment data does not provide a consolidated view of all major MIS program courses, as each semester only a subset of these courses are offered. Additionally, not all program outcomes were achieved, as some of these outcomes, such as outcome "g", are related to the College core and University elective courses for which we do not have assessment data. By applying the $65 \%$ level as the achievement level, outcomes a, b, c, h, i, and $\mathrm{j}$ have not been achieved. Furthermore, outcome (a) has the lowest achievement figures.

Table 7: Course contribution to Program outcome Assessment (\%) Spring 2006/2007

\begin{tabular}{|c|c|c|c|c|c|c|c|c|c|c|c|}
\hline \multirow{2}{*}{$\begin{array}{l}\text { Program } \\
\text { Outcomes }\end{array}$} & \multicolumn{11}{|c|}{ Course Codes (last three digits) } \\
\hline & 102230 & 231330 & 331 & 332 & 333 & 337 & 338 & 430 & 432 & $436 \quad 439$ & AVG \\
\hline $\mathrm{a}$ & 67.44 & 74.80 & 73.46 & 679.36 & & $\underline{63.35}$ & 68.00 & 70.15 & 80.74 & 89.0473 .49 & 73.98 \\
\hline $\mathrm{b}$ & 67.44 & 76.11 & 73.46 & 680.25 & & $\underline{63.35}$ & 68.92 & 71.50 & 77.93 & 89.0473 .09 & 74.11 \\
\hline $\mathrm{c}$ & & 72.2 & 80.91 & 181.05 & & & & 65.78 & 75.00 & 73.33 & 74.72 \\
\hline $\mathrm{d}$ & & 66.59 & & 81.05 & & & & & 90.99 & 92.22 & 82.71 \\
\hline \multicolumn{12}{|l|}{$\mathrm{e}$} \\
\hline$f$ & & 66.59 & & & & & & & 90.99 & & 78.79 \\
\hline $\mathrm{g}$ & & 66.59 & & & & & & & & & 66.59 \\
\hline $\mathrm{h}$ & & & & & & 66.39 & 72.81 & & & & 69.6 \\
\hline $\mathrm{i}$ & 66.36 & & & & & 66.11 & 70.49 & 79.33 & & 69.03 & 70.26 \\
\hline j & 65.9 & 69.67 & 73.15 & 579.36 & & 65.60 & 70.08 & 75.20 & 83.89 & 89.0476 .28 & 74.82 \\
\hline $\mathrm{k}$ & & & & 77.68 & & & & 79.33 & & 92.22 & 83.07 \\
\hline Average: & & & & & & & & & & & 74.86 \\
\hline
\end{tabular}

By applying the $65 \%$ level as the achievement level, outcomes $\mathrm{a}$, and $\mathrm{b}$ have not been achieved. 
Table 8: Course contribution to Program outcome Assessment (\%) Spring 2007/2008

\begin{tabular}{|c|c|c|c|c|c|c|c|c|c|c|c|c|c|}
\hline \multirow{2}{*}{$\begin{array}{l}\text { Prog. } \\
\text { Outcomes }\end{array}$} & \multicolumn{13}{|c|}{ Course Codes (last three digits) } \\
\hline & 102 & $230 \quad 231$ & 330 & 331 & 332 & 333 & 337 & 338 & 430 & 432 & 436 & 439 & AVG \\
\hline $\mathrm{a}$ & & 68.35 & 69.62 & 73.01 & 72.22 & 80.05 & & 75.75 & & 83.66 & & 70.25 & 74.11 \\
\hline $\mathrm{b}$ & & 68.35 & 75.27 & 70.01 & 78.07 & 83.37 & & 90.36 & & 82.50 & & 69.18 & 77.14 \\
\hline c & & & 71.37 & 71.00 & 81.31 & & & & & 83.93 & & 74.19 & 76.36 \\
\hline d & & & 80.00 & & 81.31 & & & & & 82.39 & & & 81.23 \\
\hline \multicolumn{14}{|l|}{ e } \\
\hline $\mathrm{f}$ & & & 80.00 & & & & & & & 82.39 & & & 81.20 \\
\hline g & & & 80.00 & & & & & & & & & & 80 \\
\hline h & & & & & & 84.01 & & 83.75 & & & & & 83.88 \\
\hline i & & 68.75 & & & & 80.66 & & 81.72 & & & & 79.69 & 77.71 \\
\hline j & & 70.86 & 60.68 & 69.50 & 72.22 & & & 82.48 & & 89.64 & & 74.25 & 74.23 \\
\hline & & & & & 81.31 & & & & & & & & 81.31 \\
\hline Average: & & & & & & & & & & & & & 78.72 \\
\hline
\end{tabular}

Table 9 and Figure 2 summarize all the four previous tables for the target course.

Table 9: Course (Database Fundamentals \& Applications) Contribution to Program Outcome Assessment (\%) For the four semesters

\begin{tabular}{lllll}
\hline Fall 2006/2007 & Spring 2006/2007 & Fall 2007/2008 & Spring 2007/2008 \\
\hline A & 85,56 & 73,46 & 80,5 & 73,01 \\
B & 81,55 & 73,43 & 80,05 & 70,01 \\
C & 85,65 & 80,91 & 68,14 & 71 \\
J & 85,58 & 73,15 & 79,43 & 69,5 \\
\hline
\end{tabular}

Figure 3: Course (Database Fundamentals \& Applications) contribution to Program outcome Assessment (\%) For the four semesters

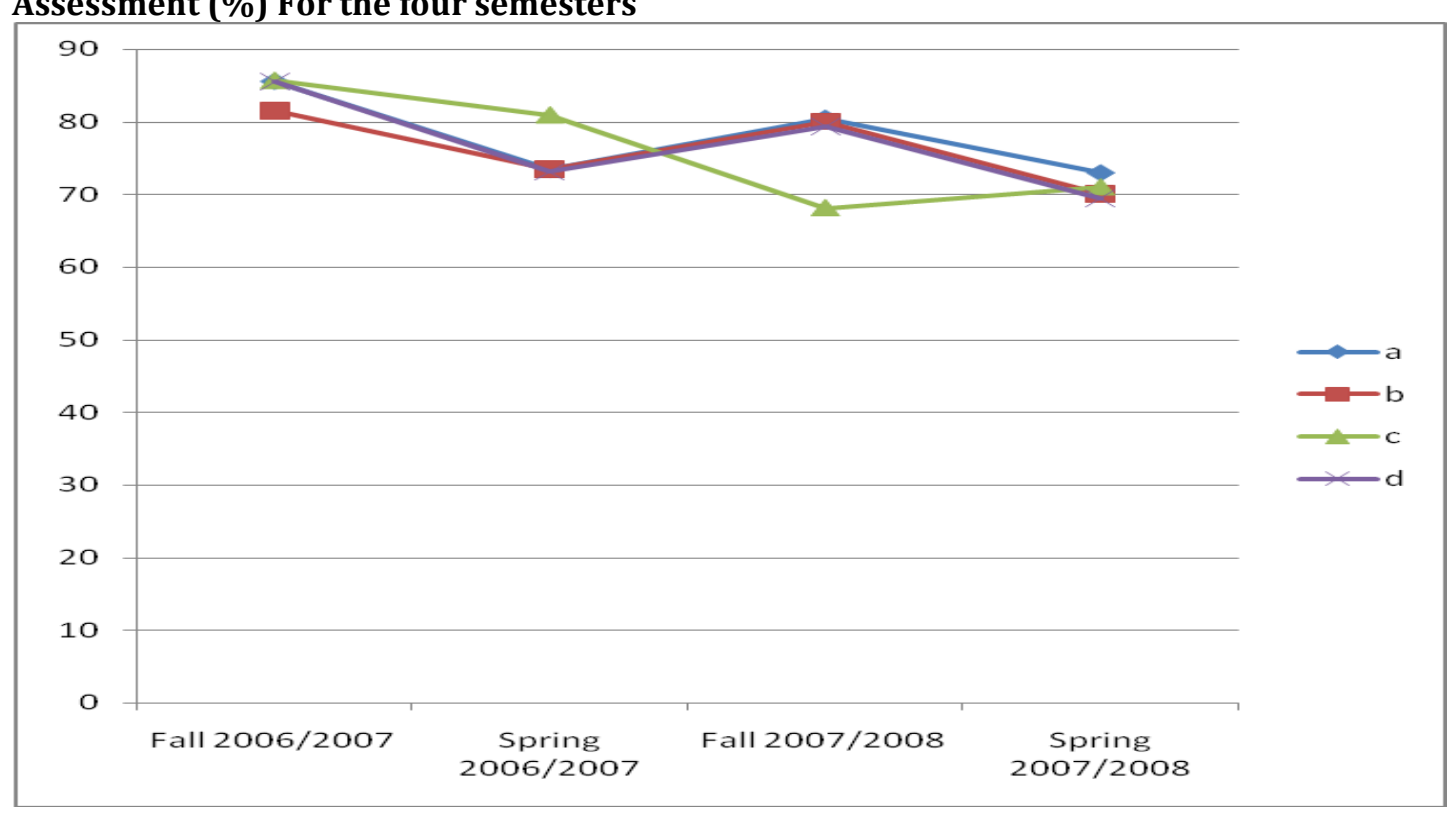

Figure 3 shows that, for the course Database Fundamentals \& Applications, the contribution of this course to the related program outcomes (a, b, j) showed a considerable decrease in the Fall Semester 2006/2007 to Spring Semester 2007/2008, while outcome c showed a slight increase for the same period. The course outcomes for the same course (see Table 5 \& Figure 1) showed a decreasing trend and action was suggested to improve the performance. Improving the performance in the course outcome may have a positive effect on the program outcome. This should be revisited for the results of fall 2008-2009. 


\section{Conclusion and Future Work}

The goal of implementing an OBE at UoS was to use these assessment instruments to improve the program over time. To measure or assess the learning outcomes, it was necessary to start with measurable and specific learning outcomes for our program and individual courses. The outcomes had to be precisely written so both educators and students would have a clear understanding of expectations. Measurement tools, techniques, instruments, and methods needed to be developed and conveyed to both the educators and students to avoid confusion. Assessment data needed to be collected regularly using multiple methods and instruments. The information derived from this analysis will be used to continually improve teaching and learning at UoS. Because this was a pilot program and represented an incremental implementation of $\mathrm{OBE}$, consistent and comparable measurement across semesters was difficult. With each semester, new elements were added to the assessment. To gain the most accurate comparison possible, data for only final exams and final projects were compared across all semesters. Additionally, overall results were compared across all semesters, with the understanding that this comparison must be taken with caution, since each semester added new assessment factors. However, measurements going forward will eventually contain all assessment elements, and comparisons that are more accurate can be made about how effective the MIS program is in meeting its learning outcomes.

The purpose of this paper was not only to report the results of the effectiveness of achieving learning outcomes, but also to report on the process of implementing an OBE in a single departmental program at UoS. However, many issues still remain to be addressed. Future research should focus on assessment tools and their comparative power and accuracy in measuring course and program outcomes. Developing measurable outcomes, as well as the process of measuring the outcomes, are both an art and science, and as such, more research is needed to explicate and refine this measurement process. Research is also needed to develop criteria and guidelines for assigning weights to the different courses making up a degree program. This will help streamline and rationalize the process of matching course outcomes with program outcomes. OBE is increasingly adopted in educational institutions and is now invariably required for accreditation. It is important, therefore, for educators to accept the challenge of developing measurable outcomes, and then to use the assessment data to continuously improve the education process. However, we forward the following caveats: 1) program outcomes should be developed first, followed by course outcomes; 2) care must be taken when matching course/program outcomes, as there is considerable subjectivity involved; 3 ) the process of measuring outcomes is potentially subject to manipulation and is not fool-proof. For example, assessment instruments can be tightened or relaxed to lower or raise student scores. Therefore, care must be taken in analyzing and drawing conclusions from such results.

\section{References}

AAHE, A. A. f. H. E. (2009). Nine principles of good practice for assessing student learning.

Acharya, C. (2003). Outcome-based Education (OBE): A new Paradigm for learning. CDTLink. National University of Singapore. Singapore.

Allen, M. (2006). Assessing general education programs. (1-10).Bolton, MA: Anker Publishing Company.

Angelo, T. A. (2002). Engaging and supporting faculty in the scholarship of assessment: Guidelines. In T. W. Banta (Ed.), Building a scholarship of assessment (185-200). San Francisco, CA: Jossey-Bass.

Astin, A. W. (1991). Assessment for excellence: The philosophy and practice of assessment and evaluation in higher education. New York, NY: American Council on Education/Macmillan.

Banta, T. W. (2002). Building a scholarship of assessment. San Francisco, CA: Jossey Bass.

Banta, T. W. (2008). Profiles of good practice in assessment. Assessment Update, 20(6), 3-4.

Barkley, E. F. (2009). Student Engagement Techniques: A Handbook for College Faculty. Wiley Publishers.

Barkley, E. (2010). Student engagement techniques: a handbook for college faculty. San Francisco: JosseyBass.

Besterfield-sacre, M. E., Larry J. S., Harvey, W., Cynthia, J., Atman, J. M., Ronald, L., Miller, B. M. O. \& Gloria, M. R. (2000). Defining the Outcomes: A framework for EC 2000. IEEE Transactions on Engineering Education, 43(2), 100-110.

David, J. P. (2009). Giving a voice to teachers and students in an outcome-based approach. ELT Journal, 63(4), 387-389.

Doherty, K. P. (2005). Beyond the accountability-improvement debate: A case study analysis of institutional response to assessment. 
Ewell, P. T. (2002). Perpetual movement: Assessment after twenty years. Paper presented at the 2002 Assessment Institute, Indianapolis, IN.

Ewell, P. T. (2008). Assessment and accountability in America today: Background and context. Paper presented at the 2008 Assessment Institute, Indianapolis, IN.

Ewell, P. T. (2009). Assessment, Accountability, and Improvement: Re-visiting the Tension (NILOA Occasional Paper No.1). Urbana, IL: University of Illinois and Indiana University, National Institute of Learning Outcomes Assessment. November 2009.

Felder, R. \& Brent, R. (2003). Designing and Teaching Courses to Satisfy the ABET Engineering Criteria. Journal of Engineering Education, 92(1), 7-18.

Hashim, R. \& Mohd-Din, M. A. (2009). Implementing Outcomes Based Education using project based learning at University of Malaya. European Journal of Scientific Research, 26(1), 80-86.

Houshangi, N. (2003). Curriculum Assessment and Enhancement at Perdue University Calumet Based On ABET 2000. Proceedings of the American Society for Engineering Education, 120-128.

Huba, M. E., Schuh, J. \& Shelley, M. (2006). Recasting doctoral education in an outcomes framework. In P. L. Maki \& N. A. Borkowski (Eds.), the assessment of doctoral education (239-272). Sterling, VA: Stylus.

Kember, D., Ho, S.S.S., Lau, C. B., Au-Yeung, M. M., Chow, M. S. \& Leung D. Y. (2009). An outcomes-based approach to curriculum development in pharmacy. American Journal of Pharmaceutical Education, 73(1).

Kuh, G. (2008). High-impact educational practices: What they are, who has access to them, and why they matter. Washington, DC: Association of American Colleges and Universities. Retrieved March 5, 2012 from http://www.neasc.org/downloads/aacu_high_impact_2008_final.pdf.

Lau G. K. (2009). The changing faces of outcomes-based learning: Teaching and learning creativity 10.20.30. The International Journal of Learning, 16(5), 125-138.

Lenning, O. T., Lee, Y. S., Micek, S. S. \& Service, A. L. (1977). A structure for the outcomes of postsecondary education. Boulder, CO: National Center for Higher Education Management Systems. Retrieved March 5, 2012 from http://www.eric.ed.gov/PDFS/ED150904.pdf.

Maki, P. L. (2002). Developing an assessment plan to learn about student learning. The Journal of Academic Librarianship, 28, 8-13.

Moore, W. S. (1994). Student and faculty epistemology in the college classroom: The Perry schema of intellectual and ethical development. In K. W. Prichard \& R. M. Sawyer (Eds.), Handbook of college teaching: Theory and applications (45-67). Westport, CT: Greenwood Press.

Oster, S. (2003). Writing measurable Learning Outcomes. Texas A\&M 3rd Annual Assessment Conference.

Pang, M., Ho, T. M. \& Ryan, M. (2009). Learning approaches and outcome-based teaching and learning: A case study in Hong Kong, China. Journal of Teaching in International Business, 1528-699 20(2), 106-122.

Perry, W. G. (1970). Forms of intellectual and ethical development in the college years: A scheme. New York, NY: Holt, Rinehart and Winston. In Rapaport, William J. William Perry's Scheme of Intellectual and Ethical Development,

Shavelson, R. (2007). Assessing student learning responsibly: from history to an audacious proposal. Change, January/February 2007, 26-33.

Shavelson, R. J. \& Huang, L. (2003). Responding responsibly to the frenzy to assess learning in higher education. Change, 35(1), 11-19.

Spady, W. \& Marshall, K. (1994). Light, not Heat, on OBE. The American School Board Journal, 181, 29-33.

Terenzini, P. (1997). Student outcomes information for policy-making (NCES 97-991). Washington, DC: U.S. Department of Education, National Center for Education Statistics.

Thurmond, V. A. \& Popkess-Vawter, D. (2003). Examination of a middle range theory: Applying Astin's input-environment-outcomes (I-E-O) model to web-based education. Journal of Nursing Informatics, 7(2).

Timm, M. D. (2009). Developing outcomes-based assessment for learner-centered education: A faculty introduction. Journal of College Student Development, 49(4), 392-394. 